\title{
Jung CHANG, Jon HALLIDAY, Mao, l'histoire inconnue
}

Paris, Éd. Gallimard, coll. NRF biographies, 2006, 844 p.

\section{Olivier Arifon}

Traducteur : Béatrice Vierne, Georges Liébert et Olivier Salvatori

\section{OpenEdition \\ Journals}

\section{Édition électronique}

URL : http://journals.openedition.org/questionsdecommunication/7388

DOI : 10.4000/questionsdecommunication.7388

ISSN : 2259-890

\section{Éditeur}

Presses universitaires de Lorraine

\section{Édition imprimée}

Date de publication : 1 juillet 2007

ISBN : 978-2-86480-829-9

ISSN : 1633-5961

\section{Référence électronique}

Olivier Arifon, « Jung Chang, Jon halliday, Mao, l'histoire inconnue », Questions de communication [En ligne], 11 | 2007, mis en ligne le 01 juillet 2007, consulté le 12 avril 2021. URL : http://

journals.openedition.org/questionsdecommunication/7388; DOI : https://doi.org/10.4000/ questionsdecommunication.7388

Ce document a été généré automatiquement le 12 avril 2021 


\section{Jung CHANG, Jon HALLIDAY, Mao, l'histoire inconnue}

Paris, Éd. Gallimard, coll. NRF biographies, 2006, 844 p.

\section{Olivier Arifon}

Traduction : Béatrice Vierne, Georges Liébert et Olivier Salvatori

\section{RÉFÉRENCE}

Jung CHANG, Jon HALLIDAY, Mao, l'histoire inconnue. Trad. de l'anglais par Béatrice Vierne, Georges Liébert, Olivier Salvatori, Paris, Éd. Gallimard, coll. NRF biographies, 2006, 844 p.

1 Chroniquer la biographie d'un homme politique qui a marqué le $\mathrm{xx}^{\mathrm{e}}$ siècle dans une revue de communication, voilà qui pourrait étonner. Nous pensons au contraire que cela peut être utile, car le monumental travail de Jung Chang et Jon Halliday peut se lire de plusieurs manières. Fruit de dix années de recherches, cet ouvrage de 844 pages comprend une importante liste de sources, avec notamment dix pages comportant les noms de personnes interviewées qui, de près ou de loin, ont été en contact avec Mao. Sur le plan méthodologique, il est difficile d'utiliser les nombreuses références qui, regroupées en fin de volume, apparaissent mal organisées. Du point de vue biographique, ce livre détaille la vie de Mao et donne un éclairage sur son état d'esprit et son caractère. La personnalité de Mao se révèle dans toutes ses dimensions : avidité $\mathrm{du}$ pouvoir, fascination pour la violence, indifférence à ses épouses et (légèrement moins) à ses enfants, anticipation des conflits, obsession de la sécurité. Mao se coule comme l'eau dans le lit de la rivière dans les modalités chinoises traditionnelles du pouvoir ; comme les empereurs avant lui, il règne par l'absence physique, le secret, la manipulation et l'arbitraire. C'est également le parcours de l'éclatante réussite du Parti communiste chinois (PCC) et de l'Armée populaire de libération qui est exposé, avec notamment le rôle permanent de Moscou, d'abord comme mentor, soutien politique et financier, devenant ensuite adversaire permanent pour le contrôle des mouvements 
révolutionnaires. À ce sujet, on mesure les différences d'approches: Moscou reste relativement modéré face aux États-Unis, tandis que Mao parle de guerre nécessaire. C'est ensuite tout le $\mathrm{xx}^{\mathrm{e}}$ siècle et ses questions que l'on parcourt; un détour asiatique qui permet de découvrir le siècle sous un autre angle, avec par exemple, les instrumentalisations de la guerre de Corée ou la question de Taiwan, ou encore et de manière très nette, la manipulation de la visite de Richard Nixon où ce dernier cède sur tous les points aux attentes des chinois.

2 L'ensemble peut également se lire avec la grille des sciences de l'information et de la communication. À la frontière de la communication et du renseignement, il faut noter que la victoire communiste sur les nationalistes tient en partie à la connaissance des codes secrets des forces de Tchang Kaï-check. De même, la gestion du temps est toute chinoise : absence aux réunions, maladie comme prétexte, refus des ordres de Moscou quand cela est nécessaire. L'ouvrage aborde aussi les mythes du communisme chinois et du maoïsme pour mieux les éclairer et les démonter. Ainsi en est-il de la Longue marche qui doit son succès à l'usage des médias, à l'évitement "de Tchang Kaï-chek, désireux de ne pas combattre, et son coût en vies humaines, selon la volonté de Mao. La construction de ces mythes doit aussi à la mise en scène de son personnage face au journaliste américain Edgar Snow, qui se fera son meilleur agent. Il faut citer le travail de destruction de l'image de Tchang Kaï-chek, qui fut réellement moderne et unificateur, au profit d'un discours du PCC, complètement différent de la réalité des actes du régime. Un autre mythe, tenace chez les analystes stratégiques, est celui de Mao conduisant les conflits contre les nationalistes en s'appuyant sur les principes du jeu de Go. L'étude des choix de Mao confrontés à ses généraux montre qu'il n'en est rien.

3 Bien entendu, la période de la révolution culturelle est analysée. On le sait, c'est d'abord un jeu de pouvoir visant à éliminer les opposants de Mao et où tous les cadres du Parti seront remplacés par des militaires. En termes de communication de masse, le livre présente les manipulations du peuple chinois qui surprendra le monde par sa ferveur et son implication (mais avait-il d'autres choix ?) et celles envers l'Occident. Voulant devenir le leader des mouvements révolutionnaires, Mao exportera les concepts (compilés dans le Petit livre rouge) dans le monde, et les partis de gauche seront ses meilleurs relais de propagation de ses idées. Toutefois, les méthodes, la brutalité et le cynisme du style maoïste se révéleront assez rapidement.

4 Enfin, cette biographie met en perspective la Chine contemporaine, donne à comprendre les manœuvres diplomatiques et présente les stratégies de communication. Les dirigeants actuels l'ont bien compris et continuent de se référer à Mao, comme le souligne l'épilogue : « Le portrait de Mao et sa dépouille continuent de dominer la place Tienanmen, au cœur de la capital chinoise. L'actuel régime communiste se déclare l'héritier de Mao et s'emploie toujours énergiquement à perpétuer son mythe » (p. 679).

5 Ancien journaliste, Mao a donc très bien géré tous les aspects de communication de son régime et de son pouvoir et l'image qu'il voulait donner de lui-même et de son pays. Aujourd'hui, le pouvoir en place suit la voie de Mao, à savoir faire de la Chine une superpuissance, en permettant toutefois de s'enrichir. En termes de recherche en sciences de l'information et de la communication, les analyses de la diplomatie et de la communication, de la régulation du pouvoir constituent des champs que la discipline pourrait explorer avec profit. 


\section{AUTEURS}

OLIVIER ARIFON

CÉRIME, université Strasbourg 3 